\title{
The Roles of Excitatory Amino Acids and Cytokines in Morphine Tolerance: Effect of Tricyclic Antidepressant Amitriptyline
}

\author{
Yueh-Hua Tai ${ }^{1}$, Wen-Jinn Liaw ${ }^{1}$, Yuan-Xiang Tao ${ }^{2}$ and Chih-Shung Wong*,1 \\ ${ }^{I}$ Department of Anesthesiology, Tri-Service General Hospital and National Defense Medical Center, Taipei, Taiwan, \\ R.O.C. ${ }^{2}$ Department of Anesthesiology and Critical Care Medicine, Johns Hopkins University School of Medicine, 720 \\ Rutland Ave., 367 Ross, Baltimore, Maryland 21205, USA
}

\begin{abstract}
Morphine is an effective analgesic in clinical practice; however, its long-term administration causes tolerance, thereby limiting its use. The development of opioid tolerance and its associated hyperalgesia has been associated with interactions between opioid receptors and excitatory amino acids or cytokines. Targeted inhibition of excitatory amino acid- and cytokine-mediated signaling pathways may allow development of novel therapeutic strategies for treating opioid tolerance. Recent studies showed that administration of amitriptyline (a tricyclic antidepressant widely used in the treatment of neuropathic pain) attenuated morphine tolerance and preserved the antinociceptive effect of morphine. This ability might be related to the effects of tricyclic antidepressants on pro-inflammatory cytokine release and glutamate transporter expression in dorsal horn during morphine tolerance. Here, we will review evidence for the role of excitatory amino acids and cytokines in the development of morphine tolerance and discuss potential mechanisms by which tricyclic antidepressants attenuate morphine tolerance.
\end{abstract}

\section{INTRODUCTION}

Morphine is one of the most potent analgesic drugs used in clinical pain management. It is often used for long-term pain management in patients with cancer pain and neuropathic pain. However, its use for treatment of chronic pain is limited by side effects, especially the development of morphine tolerance (that is, a loss of analgesic effectiveness) [1]. Morphine tolerance is a complex physiological response that involves a within-system and a between-system adaptation [2]. The within-system adaptations, which include opioid receptors uncoupling from G-proteins and receptor down-regulation, are well-known mechanisms of opioid tolerance [3, 4]. Recent studies have proposed that betweensystem adaptations, such as the pain facilitatory systems (opiate-activated opponent systems) also may play an important role in the development of opioid tolerance. Excitatory amino acids (EAAs), their activated receptors [e.g., N-methyl-D-asparate (NMDA) receptors], and the subsequent downstream signals (e.g., nitric oxide) are probably involved in a between-system mechanism of opioid tolerance [5]. In addition, pro-inflammatory cytokines released from activated glial cells after repeated morphine injections have been reported to participate in this betweensystem mechanism [6].

Tricyclic antidepressants are widely used to treat chronic pain such as neuropathic and inflammatory pain conditions in clinical [7,8]. According to a recent Cochrane metaanalysis, which included 61 studies, tricyclic antidepressants are considered to be efficient for neuropathic pain relief on

*Address correspondence to this author at the Department of Anesthesiology, Tri-Service General Hospital and National Defense Medical Center, Taipei, Taiwan, R.O.C; Tel: +886-2-87927008;

Fax: +886-2-87927009; E-mail: w82556@ndmctsgh.edu.tw the basis of sufficient class I trials [9]. Researches showed that tricyclic antidepressants amitriptyline possesses potent sodium channel blocking activity and a potent local anesthetic effect than bupivacaine [10-12]. Intrathecal administration of amitriptyline effectively attenuates pain and thermal hyperalgesia in rat inflammatory and neuropathic pain models, particularly when combined with opiates and clonidine [13-15]. Tricyclic antidepressants produce analgesia by various mechanisms involving NMDA receptors, biogenic amines, opioids, inflammatory mediators, and substance $\mathrm{P}[12,16,17]$. New studies have revealed that intrathecal administration of the tricyclic antidepressants amitriptyline attenuates the development of morphine tolerance through targeted inhibition of EAA- and proinflammatory cytokine-mediated signaling pathways. Here, we will review evidence for the role of EAAs and cytokines in the development of morphine tolerance and discuss potential mechanisms by which amitriptyline might prevent morphine tolerance.

\section{EXCITATORY AMINO ACIDS AND MORPHINE TOLERANCE: EFFECT OF AMITRIPTYLINE}

EAAs such as glutamate and aspartate are the principal excitatory neurotransmitters in neuronal circuits; they are involved in a variety of central nervous system functions, including pain modulation [18]. Glutamate and aspartate have been shown to be involved in nociception transmission in the spinal cord $[19,20]$. A large number of glutamate binding sites exist in the substantia gelatinosa of the rat spinal cord and correlate well with the projection areas of primary glutamatergic terminals [21]. Intrathecal injection of EAAs results in hyperalgesia and allodynia in rats [19]. Although four days of spinal morphine infusion in rats had little effect on the basal level of EAAs [22], post-treatment with naloxone evoked a reliable, time-dependent increase in dialysate glutamate and taurine concentration, but not other 
amino acids in chronic intrathecal morphine-infused rats [22]. No effect was seen in saline-infused rats.

Consistently, we have found that acute morphine treatment increases the levels of the dopamine metabolite DOPAC and glutamate in the striatum, nucleus accumbens, and locus coeruleus neurons in naloxone-precipitated morphine-tolerant rats [23]. Intrathecal morphine challenge induced the release of glutamate and aspartate in spinal cord of morphine-tolerant rats and produced a loss of morphine's analgesic effect [24]. Co-administration of morphine with the NMDA antagonist MK-801 not only attenuated morphine tolerance development, but also blocked morphine-induced spinal EAAs release [24-26]. In a clinical setting, increased glutamate and aspartate concentrations in the cerebral spinal fluid and a reduction in the analgesic effect of morphine were observed in terminal cancer pain patients who received long-term intrathecal morphine for pain relief [27]. These findings indicate a correlation between spinal cord EAA release and the development of morphine tolerance. Recently, amitriptyline has been shown to prevent the development of morphine tolerance [28, 29]. Moreover, pre- and post-treatment of amitriptyline attenuated the morphine-evoked EAA release in morphinetolerant rats $[28,29]$. These findings suggest that amitriptyline produced prevention of morphine tolerance might result from a reduction in spinal EAA release.

Glutamate mediates its actions through two types of receptor, metabotropic glutamate receptors (mGluRs) and ionotropic glutamate receptors (iGluRs). The mGluRs mediate slow glutamate response by coupling to a variety of signal transduction system via $G$ proteins [30]. As a consequence, mGluR signaling plays an important role in the processing underlying synaptic plasticity [31]. Studies have shown that mGluR 5 antagonists inhibited inflammatory and neuropathic pain in rats $[32,33]$ and mice $[34,35]$. In addition, acute and chronic administration of mGluR5, mGluR2/3 and mGluR7 antagonist also attenuates allodynia and hyperalgesia and potentiates morphine's efficacy in neuropathic pain mice [36]. The iGluRs, mediate fast excitatory glutamate response, are subdivided into NMDA, AMPA ( $\alpha$-amino-3-hydroxyl-5-methyl-4-isoxazole-propionate) and kainite receptors. Activation of spinal iGluRs plays a crucial role in the development of tolerance to the analgesic effects of morphine $[5,37,38]$. The induction of EAA release by repeated morphine injections could activate glutamate receptors in the spinal cord. Co-administration of morphine with an NMDA receptor antagonist (MK-801) and NMDA receptor/glycine site antagonist (ACEA-1328) effectively prevents the development of morphine tolerance in several animal models, including rats, mice, and guinea pigs [39-43]. Furthermore, competitive NMDA receptor antagonist LY274614 prevent antinociceptive tolerance to the highly selective $\mu$-opioid antagonist DAMGO [44]. The competitive AMPA receptor antagonist LY293558 attenuates and reverses the analgesic tolerance to morphine [37]. Deletion of the glutamate receptor 5 subunit of kainite receptor also prevents morphine tolerance [38]. Thus, it is clear that EAA-stimulated iGluRs receptor activation within the spinal cord is involved in the development of morphine tolerance. Amitriptyline and other tricyclic antidepressants have shown with high binding affinity to NMDA receptors [45], and function as NMDA antagonists [46, 47]. However, the underlying mechanisms of amitriptypline mediated effects via regulating the glutamate receptor in morphine tolerance still need further investigation.

\section{GLUTAMATE TRANSPORTER EXPRESSION AND MORPHINE TOLERANCE: EFFECT OF AMITRIP- TYLINE}

The termination of glutamatergic transmission and clearance of excess synaptic glutamate depend on highcapacity $\mathrm{Na}$-dependent glutamate transporters, including GLAST, GLT-1, and EAAC1. These three glutamate transporters are expressed at the highest density within the superficial dorsal horn of spinal cord in rats and mice, especially in the pain-related regions [48, 49]. GLT-1 and GLAST are exclusively distributed in glial cells at persynaptic sites in the superficial dorsal horn [49]. EAAC1, in addition to being expressed in the spinal cord neurons, is detected in the dorsal root ganglion and distributed predominantly in the small dorsal root ganglion neurons (but not in dorsal root ganglion glial cells) [48]. Chronic morphine administration, given by either intrathecal bolus injections or continuous infusion, induces dose-dependent down-regulation of glutamate transporter protein expression in the spinal cord dorsal horn $[50,51]$. Administration of glutamate transporter activators (e.g., MS-153 or riluzole) attenuates the development of morphine tolerance and associated thermal hyperalgesia $[51,52]$. In contrast, disturbance of spinal glutamate transporter activity by the glutamate transporter inhibitor 1-trans-pyrrolidine-2-4dicarboxylate potentiates the development of both morphine tolerance and thermal hyperalgesia [51]. These results indicate that down-regulation of spinal glutamate transporters after repeated morphine injection might contribute to the development of morphine tolerance.

Interestingly, co-administration of amitriptyline with morphine has been shown to up-regulate the expression of glutamate transporters in chronically morphine-infused rats [53]. The NF-KB pathway might be involved in this effect. $\mathrm{NF}-\kappa \mathrm{B}$ is known to activate many genes in the response to inflammation and tissue injury. A consensus NF- $\mathrm{KB}$ site is found in the $5^{\prime}$ untranslated region of the GLT-1 gene [54]. NF- $\kappa B$-dependent GLT-1 expression is positively regulated by epidermal growth factor and negatively regulated by TNF- $\alpha$. [54]. TNF- $\alpha$ recruits N-myc (transcription regulatory factor) to the glutamate transporter promoter, which leads to the conversion of NF-kB to a transcriptional repressor and results in reduction of GLAST and GLT-1 expression [55, 56]. The serine/threonine kinase (Akt, also called protein kinase $\mathrm{B}$ ) activates NF- $\kappa \mathrm{B}$ via I $\kappa \mathrm{B}$ phosphorylation, resulting in I $\kappa$ B degradation and induction of GLT-1 (but not GLAST) expression [57]. Co-infusion of amitriptyline with morphine significantly increases phosphorylated IкB $\alpha$ level, promotes I $\kappa \mathrm{B} \alpha$ degradation, leads to translocation of the activated NF$\kappa \mathrm{B}$ complex to its nuclear target, and results in up-regulation of glutamate transporter expression. Blockade of NF- $\mathrm{KB}$ activation by Ro 1069920 completely prevented amitriptyline-induced GLAST and GLT-1 up-regulation and even further down-regulated the expression of all three glutamate transporters in chronically morphine-infused rats. These studies suggest that amitriptyline up-regulates glutamate transporter expression, at least in part, by enhancing NF- $\mathrm{kB}$ transcription in the morphine-tolerant rats [53]. 
Protein kinase A (PKA) and protein kinase C (PKC) might also be involved in amitriptyline-induced upregulation of surface glutamate transporter expression in the morphine tolerant animals. Activation of PKA and PKC regulates glutamate transporter trafficking between the cytoplasm and the plasma membrane of neurons and glial cells [58-61]. PKC activation decreases both the activity and cell surface expression of GLT-1 in a variety of systems [6264]. This decrease might be caused by the formation of PKC $\alpha$-GLT-1 complexes, which induce the PKC-dependent internalization of GLT-1 [59]. Interestingly, PKA inhibition reduces cell surface expression of EAAC1 and GLAST but increases the cell surface expression of GLT-1 [65]. In morphine-tolerant rats, acute pretreatment with the PKC inhibitor Gš6805 increases GLT-1 cell surface expression and EAA uptake after morphine challenge [28], whereas acute treatment with PKA inhibitor H89 increases GLAST expression on the plasma membrane in morphine-tolerant rats [28]. The tricyclic antidepressants imipramine was demonstrated to inhibit PKC activity in rat cerebral cortical slices [66]. Furthermore, repeated treatment with desipramine or fluoxetine decreased PKC activity in both soluble and particulate fractions of rat cerebral cortex and hippocampus [67]. We found that amitriptyline inhibited the expression of $\mathrm{PKC} \alpha, \beta \mathrm{II}$, and $\gamma$ protein in morphine-tolerant rat spinal cord but had no effect on PKA expression [28]. Similarly, Budziszewska et al. failed to observe the inhibitory effect of imipramine on PKA expression when they examined glucocorticoid receptor-mediated gene transcription [68]. Moreover, acute amitriptyline treatment inhibited the phospho-PKA and PKC expression in morphine-tolerant rats [28]. These findings suggest that acute amitriptyline treatment preserves morphine's antinociceptive effect in morphine-tolerant rats by inhibiting the expression of phospho-PKA and PKC and by subsequent induction of GLAST and GLT-1 trafficking to the glial cell surface. The latter action enhances EAA uptake from the synaptic cleft and reduces spinal EAA release.

\section{CYTOKINES AND MORPHINE TOLERANCE: EF- FECT OF AMITRIPTYLINE}

The activation of spinal glia, a characteristic response observed during central neuroimmune activation and neuroinflammation, may mediate and/or modulate the pathogenesis of persistent pain states [6, 69] and CNS neuronal plasticity via neural-glial interaction [70]. In the spinal cord, immune cells (astrocytes, and microglia) might be activated in response to diverse noxious stimuli and proinflammatory cytokines, such as TNF- $\alpha$, IL-1 $1 \beta$, and IL-6. Pro-inflammatory cytokines act in a paracrine fashion; they potentiate cells far from their release site to release painrelated transmitters or substances (e.g. nitric oxide, prostaglandins, and EAAs) from primary afferent terminals [71]. Studies have shown that TNF- $\alpha$ and IL-6 regulate excitatory and inhibitory neurotransmission, respectively, and IL-1 $\beta$ regulates both excitatory and inhibitory neurotransmission. These cytokines maintain persistent pain by inducing CREB phosphorylation and regulating CREBmediated gene transcription [72, 73]. TNF- $\alpha$ also shows to stimulate the endogenous intracellular prostaglandins production, thus sensitizing/activating sensory neurons by suppressing the sustained potassium current in nociceptive
DRG neurons [74]. The role of pro-inflammatory cytokines in the development of morphine tolerance is well documented [75, 76]. Chronic morphine administration activates glial cells and up-regulates pro-inflammatory cytokine expression in the spinal cord [77, 78]. Administration of glial metabolic inhibitors fluorocitrate (a nonselective metabolic inhibitor of astrocytes) or propentofylline (xanthine derivative) reverses the development of morphine tolerance in rats [77, 78]. In addition, co-administration of anti-IL-6 antibody, soluble TNF receptors, anti-inflammatory cytokine IL-10, or IL-1 receptor antagonist IL-1ra attenuates opioid tolerance and prevents hyperalgesia and allodynia [6, 78]. Chronic subcutaneous morphine administration increases microglial and astrocytic immunoreactivity and pro-inflammatory cytokine mRNA and protein expression in spinal cord to a greater degree in nerve-injured rats given morphine than in untreated nerve-injured rats $[6,78]$, indicating a possible synergistic effect of opioid administration on the nerve injury-induced activation of spinal glia cells and cytokine production.

We found that amitriptyline-induced attenuation of morphine tolerance and preservation of morphine's antinociceptive effect might be associated with regulation of spinal pro-inflammatory immune response [29]. Coadministration of amitriptyline with morphine increases the expression of IL-10 in non-activated microglia, activates the p38 mitogen-activated protein kinase (MAPK) pathway (but not ERK, p-ERK, JNK, or p-JUK), and heme oxygenase-1 (HO-1) in neurons, and inhibits the pro-inflammatory cytokine expression in morphine-infused rats [79]. Neutralization of IL-10 expression and blockade of p38 MAPK activation reverses the amitriptyline-induced increase in HO-1 expression and the inhibition of pro-inflammatory cytokine expression. Moreover, inhibition of IL-10 expression, p38 MAPK activation, or HO-1 expression partially blocks the inhibitory effect of amitriptyline on morphine's antinociceptive tolerance. These results suggest that the suppressive effect of amitriptyline on the proinflammatory cytokine production in morphine-infused rats is mediated through an increase in IL-10 protein expression in microglia. The IL-10 subsequently activates the neuronal p38 MAPK pathway and increases neuronal HO-1 expression [79].

Studies have suggested that IL-10 and HO-1 produce a positive feedback to amplify the anti-inflammatory effect by up-regulation of carbon monoxide- and p38 MAPKdependent mechanisms [80, 81]. The transcriptional activation of HO-1 is mediated by the ERK, JNK, and p38 MAPK pathways [82, 83], and p38 MAPK is a key mediator of cellular stresses, such as inflammation and apoptosis. Both in vitro and in vivo studies have shown that $\mathrm{p} 38$ MAPK regulates the production of proinflammatory cytokines, nitric oxide, and prostaglandin E2, by increasing of cytokines release or mRNA transcription [84-86]. As known, increasing of proinflammatory cytokines expression in the spinal cord is associated with neuropathic pain and morphine tolerance [87, 88]. p38 MAPK is activated in neuropathic pain by peripheral inflammation and nerve injury [89-91]. Morphine tolerance associated microglia activation is also activated via p38 MAPK signaling pathway [92]. Inhibition of p38 MAPK was considered to be a potential therapeutic 
target for anti-inflammatory therapy [93]. However, contradictory results were reported. Treatment with a p38 MAPK inhibitor resulted in an enhancement of TNFaproduction in mast cells [94]. Moreover, inhibition of p38 MAPK resulted in a reduction of cytokine production from mast cells, but increase cytokine release from lippolysaccharide-activated macrophages [95]. These results suggest that p38 MAPK possesses both pro-inflammatory and anti-inflammatory characteristics, it plays different roles in different inflammatory conditions, depending on the cell type and applied stimulus.

Communication between neurons and glia involves ion flux, neurotransmitters, cell adhesion molecules, and specialized signaling molecules released from synaptic and nonsynaptic regions of neurons [70, 73, 96]. Morphineinduced glia activation and pro-inflammatory cytokine release are also caused by induction of neuronal fractalkine release [87]. Fractalkines, expressed in spinal neurons, produce a diffusible signal that activates nearby microglia, and then release pro-inflammatory cytokines [97]. These results suggest that morphine indirectly affects glia function via chemokines to conduct neuron-glia communication. Activated neuronal $\mathrm{PKC} \gamma$ acts as an important mediator to modulate the neuron-glia communication, which increases astrocyte reactivity following repeated morphine treatment, and this neuron-glia communication may be responsible for the development of morphine tolerance [98]. Together from our previous studies [79], we suggest that amitriptyline modulates neuroimmune responses via a two-way communication between glial and neurons. Amitriptyline stimulates microglia releasing of anti-inflammatory cytokine IL-10 via a paracrine-manner, and increases neuron phopho-p38 MAPK expression, which induces up-regulation of HO-1, via carbon monoxide, and exerts negative feedback control of microglia activity and inhibits pro-inflammatory cytokine expression.

\section{CONCLUSIONS}

Currently available medications for the management of chronic pain, in particular for the neuropathic pain, are either inadequate or with unbearable side effects. Tricyclic antidepressants are known to be effective adjuvant for the treatment of chronic neuropathic pain in clinical practice [99, 100]. The data from our laboratory and those of others have shown that the combined treatment of tricyclic antidepressants amitriptyline with morphine preserves the antinociceptive effect of morphine and reduces morphine tolerance. The potential mechanisms by which amitriptyline attenuates morphine tolerance may be involved in inhibition of pro-inflammatory cytokine expression thought activation p38 MAPK pathway and consequently increases neuron HO1 expression, activation of $\mathrm{NF}-\kappa \mathrm{B}$ and prevention of glutamate transporter down-regulation, and even up-regulation of glial GTs GLAST and GLT-1 expression, thus attenuating

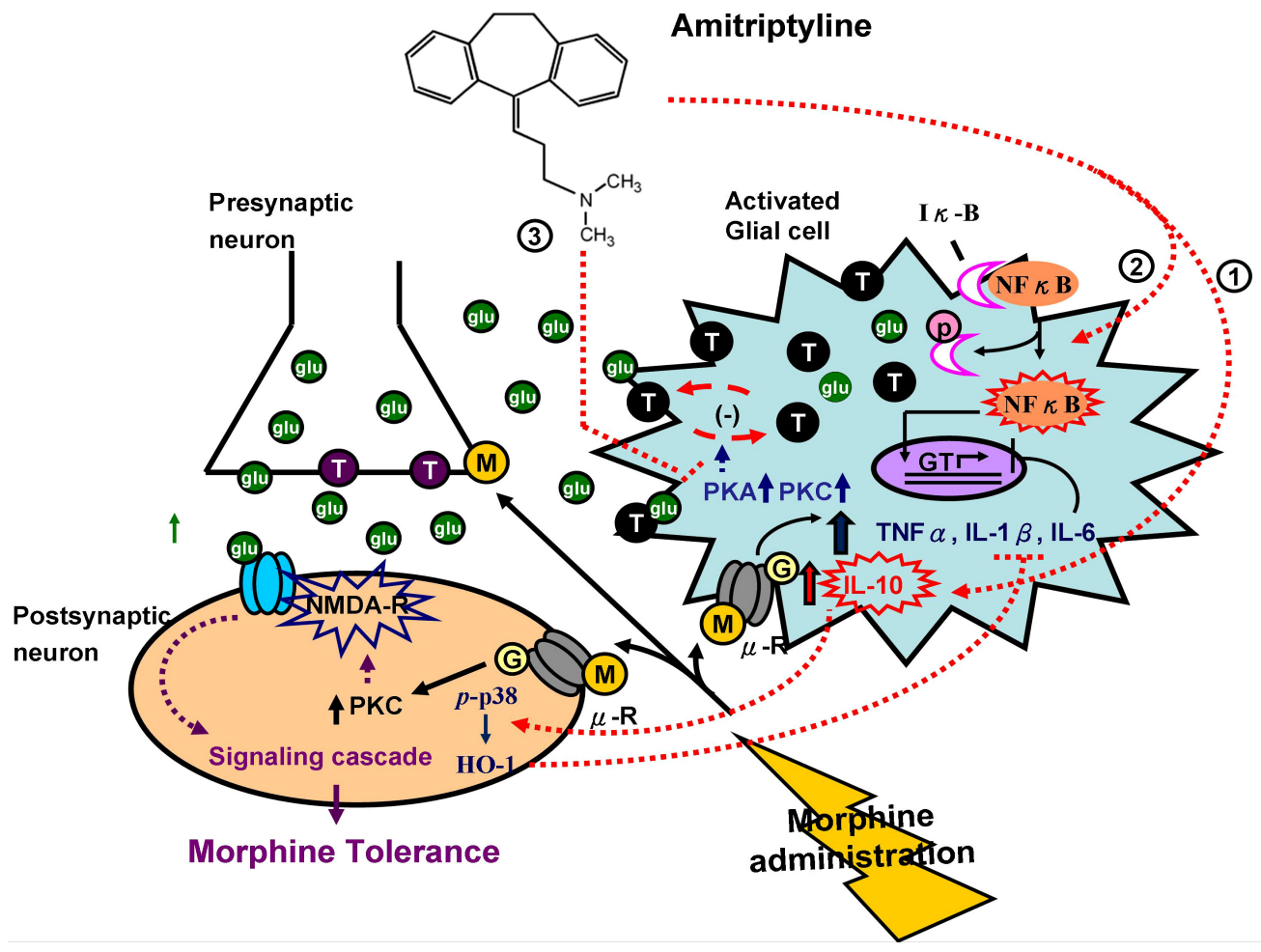

Fig. (1). Schematic diagram of proposed cellular mechanisms by which tricyclic antidepressants such as amitriptyline might attenuate the development of morphine tolerance. These mechanisms include: (1) inhibiting the expression of pro-inflammatory cytokines TNF $\alpha$, IL-1 $\beta$, and IL-6 and increasing IL-10 expression via the p38 MAPK-HO-1 signal transduction cascade; (2) activating NF- $\mathrm{B}$, preventing glutamate transporter down-regulation, and up-regulating expression of glutamate transporters GLAST and GLT-1 in glial cells; and (3) preventing phospho-PKA and PKC expression, thereby promoting GLAST and GLT-1 trafficking to the glial cell surface. Normal or over-expression of GLAST and GLT-1 in glial cell membranes maintains glutamate transporter uptake activity, reduces spinal excitatory amino acid release, and decreases NMDA receptor activation in spinal cord in morphine-infused rats. Abbreviations: G, G-protein-coupled receptor; M, morphine; glu, glutamate; T, glutamate transporter; NMDA-R, N-methyl-D-aspartate receptor. 
the morphine-evoked EAA accumulation in morphine tolerant rat CSF (Fig. 1). Evidence suggests that tricyclic antidepressants such as amitripyline may be useful as an adjuvant in combination with opioids for the treatment of patients who need long-term opioid treatment for chronic pain management. Preclinical studies have successfully elucidated some of the molecular mechanisms of tricyclic antidepressants and its effects on pain mechanism [101]. Translational research is, as in other domains of medicine, a key for further improvement on the treatment of morphine tolerance with amitriptyline.

\section{ACKNOWLEDGEMENTS}

This work was supported by Tri-Service General Hospital, Taiwan (TSGH-C97-13-S01) and National Science Council, Taiwan (NSC 95-2314-B-016-045-MY3) and National Institutes of Health Grants (NS 058886 and NS 057343) (YXT). The authors thank Claire Levine, MS, for her editorial assistance.

\section{REFERENCES}

[1] Ossipov MH, Lai J, King T, et al. Antinociceptive and nociceptive actions of opioids. J Neurobiol 2004; 61: 126-48.

[2] Koob GF, Bloom FE. Cellular and molecular mechanisms of drug dependence. Science 1988; 242: 715-23.

[3] Gintzler AR, Chakrabarti S. Opioid tolerance and the emergence of new opioid receptor-coupled signaling. Mol Neurobiol 2000; 21: 21-33.

[4] Nestler EJ, Aghajanian GK. Molecular and cellular basis of addiction. Science 1997; 278: 58-63.

[5] Hsu MM, Wong CS. The roles of pain facilitatory systems in opioid tolerance. Acta Anaesthesiol Sin 2000; 38: 155-66.

[6] Raghavendra V, Rutkowski MD, DeLeo JA. The role of spinal neuroimmune activation in morphine tolerance/hyperalgesia in neuropathic and sham-operated rats. J Neurosci 2002; 22: 9980-89.

[7] Bryson HM, Wilde MI. Amitriptyline. A review of its pharmacological properties and therapeutic use in chronic pain states. Drugs Aging 1996; 8: 459-76.

[8] Onghena P, Van Houdenhove B. Antidepressant-induced analgesia in chronic non-malignant pain: a meta-analysis of 39 placebocontrolled studies. Pain 1992; 49: 205-19.

[9] Saarto T, Wiffen PJ. Antidepressants for neuropathic pain. Cochrane Database Syst Rev 2007; (4)CD005454.

[10] Estebe JP, Gentili ME, Le Corre P, Leduc C, Moulinoux JP, Ecoffey C. Contralateral effect of amitriptyline and bupivacaine for sciatic nerve block in an animal model of inflammation. $\mathrm{Br} \mathrm{J}$ Anaesthesiol 2004; 93: 705-9.

[11] Gerner P, Mujtaba M, Sinnott CJ, Wang GK. Amitriptyline versus bupivacaine in rat sciatic nerve blockade. Anesthesiology 2001; 94 : 661-67.

[12] Sudoh Y, Cahoon EE, Gerner P, Wang GK. Tricyclic antidepressants as long-acting local anesthetics. Pain 2003; 103: 49-55.

[13] Eisenach JC, Gebhart GF. Intrathecal amitriptyline. Antinociceptive interactions with intravenous morphine and intrathecal clonidine, neostigmine, and carbamylcholine in rats. Anesthesiology 1995; 83: 1036-45.

[14] Esser MJ, Sawynok J. Acute amitriptyline in a rat model of neuropathic pain: differential symptom and route effects. Pain 1999; 80: 643-53.

[15] Gray AM, Spencer PS, Sewell RD. The involvement of the opioidergic system in the antinociceptive mechanism of action of antidepressant compounds. Br J Pharmacol 1998; 124: 669-74.

[16] Sawynok J, Esser MJ, Reid AR. Antidepressants as analgesics: an overview of central and peripheral mechanisms of action. J Psychiatry Neurosci 2001; 26: 21-29.

[17] Sawynok J, Reid AR, Esser MJ. Peripheral antinociceptive action of amitriptyline in the rat formalin test: involvement of adenosine. Pain 1999; 80: 45-55.

[18] Fundytus ME. Glutamate receptors and nociception: implications for the drug treatment of pain. CNS Drugs 2001; 15: 29-58.
[19] Aanonsen LM, Lei S, Wilcox GL. Excitatory amino acid receptors and nociceptive neurotransmission in rat spinal cord. Pain 1990; 41: 309-21.

[20] Collingridge GL, Singer W. Excitatory amino acid receptors and synaptic plasticity. Trends Pharmacol Sci 1990; 11: 290-296.

[21] Greenamyre JT, Young AB, Penney JB. Quantitative autoradiographic distribution of $\mathrm{L}-\left[{ }^{3} \mathrm{H}\right]$ glutamate-binding sites in rat central nervous system. J Neurosci 1984; 4: 2133-44.

[22] Jhamandas KH, Marsala M, Ibuki T, Yaksh TL. Spinal amino acid release and precipitated withdrawal in rats chronically infused with spinal morphine. J Neurosci 1996; 16: 2758-66.

[23] Huang NK, Tseng CJ, Wong CS, Tung CS. Effects of acute and chronic morphine on DOPAC and glutamate at subcortical DA terminals in awake rats. Pharmacol Biochem Behav 1997; 56: 36371.

[24] Wen ZH, Chang YC, Cherng CH, Wang JJ, Tao PL, Wong CS. Increasing of intrathecal CSF excitatory amino acids concentration following morphine challenge in morphine-tolerant rats. Brain Res 2004; 995: 253-59.

[25] Wen ZH, Wu GJ, Chang YC, Wang JJ, Wong CS. Dexamethasone modulates the development of morphine tolerance and expression of glutamate transporters in rats. Neuroscience 2005; 133: 807-17.

[26] Lin JA, Lee MS, Wu CT, et al. Attenuation of morphine tolerance by intrathecal gabapentin is associated with suppression of morphine-evoked excitatory amino acid release in the rat spinal cord. Brain Res 2005; 1054: 167-73.

[27] Wong CS, Chang YC, Yeh CC, Huang GS, Cherng CH. Loss of intrathecal morphine analgesia in terminal cancer patients is associated with high levels of excitatory amino acids in the CSF. Can J Anaesthesiol 2002; 49: 561-65.

[28] Tai YH, Wang YH, Tsai RY, et al. Amitriptyline preserves morphine's antinociceptive effect by regulating the glutamate transporter GLAST and GLT-1 trafficking and excitatory amino acids concentration in morphine-tolerant rats. Pain 2007; 129: 34354 .

[29] Tai YH, Wang YH, Wang JJ, Tao PL, Tung CS, Wong CS, Amitriptyline suppresses neuroinflammation and up-regulates glutamate transporters in morphine-tolerant rats. Pain 2006; 124: 77-86.

[30] Dale LB, Babwah AV, Ferguson SS. Mechanisms of metabotropic glutamate receptor desensitization: role in the patterning of effector enzyme activation. Neurochem Int 2002; 41: 319-26.

[31] Riedel G. Function of metabotropic glutamate receptors in learning and memory. Trends Neurosci 1996; 19: 219-24.

[32] Sevostianova N, Danysz W. Analgesic effects of mGlu1 and mGlu5 receptor antagonists in the rat formalin test. Neuropharmacology 2006; 51: 623-30.

[33] Zhu CZ, Wilson SG, Mikusa JP, et al. Assessing the role of metabotropic glutamate receptor 5 in multiple nociceptive modalities. Eur J Pharmacol 2004; 506: 107-18.

[34] Bhave G, Karim F, Carlton SM, Gereau RWt. Peripheral group I metabotropic glutamate receptors modulate nociception in mice. Nat Neurosci 2001; 4: 417-23

[35] Varty GB, Grilli M, Forlani A, et al. The antinociceptive and anxiolytic-like effects of the metabotropic glutamate receptor 5 (mGluR5) antagonists, MPEP and MTEP, and the mGluR1 antagonist, LY456236, in rodents: a comparison of efficacy and side-effect profiles. Psychopharmacology (Berl) 2005; 179: 207-17.

[36] Osikowicz M, Mika J, Makuch W, Przewlocka B. Glutamate receptor ligands attenuate allodynia and hyperalgesia and potentiate morphine effects in a mouse model of neuropathic pain. Pain 2008; 139: 117-26.

[37] Kest B, McLemore G, Kao B, Inturrisi CE. The competitive alphaamino-3-hydroxy-5-methylisoxazole-4-propionate receptor antagonist LY293558 attenuates and reverses analgesic tolerance to morphine but not to delta or kappa opioids. J Pharmacol Exp Ther 1997; 283: 1249-55.

[38] Bogulavsky JJ, Gregus AM, Kim PT, Costa AC, Rajadhyaksha AM, Inturrisi CE. Deletion of the glutamate receptor 5 subunit of kainate receptors affects the development of morphine tolerance. J Pharmacol Exp Ther 2009; 328: 579-87.

[39] Marek P, Ben-Eliyahu S, Gold M, Liebeskind JC. Excitatory amino acid antagonists (kynurenic acid and MK-801) attenuate the development of morphine tolerance in the rat. Brain Res 1991; 547: 77-81. 
[40] Marek P, Page GG, Ben-Eliyahu S, Liebeskind JC. N-methyl-Daspartic acid (NMDA) receptor antagonist MK-801 blocks nonopioid stress-induced analgesia. I. Comparison of opiate receptordeficient and opiate receptor-rich strains of mice. Brain Res 1991; 551: 293-96.

[41] Tanganelli S, Antonelli T, Morari M, Bianchi C, Beani L. Glutamate antagonists prevent morphine withdrawal in mice and guinea pigs. Neurosci Lett 1991; 122: 270-72.

[42] Trujillo KA, Akil $\mathrm{H}$. Inhibition of morphine tolerance and dependence by the NMDA receptor antagonist MK-801. Science 1991; 251: 85-87.

[43] Lutfy K, Doan P, Weber E. ACEA-1328, a NMDA receptor/glycine site antagonist, acutely potentiates antinociception and chronically attenuates tolerance induced by morphine. Pharmacol Res 1999; 40: 435-42.

[44] Mao J, Price DD, Lu J, Mayer DJ. Antinociceptive tolerance to the mu-opioid agonist DAMGO is dose-dependently reduced by MK801 in rats. Neurosci Lett 1998; 250: 193-96.

[45] Reynolds IJ, Miller RJ. Tricyclic antidepressants block N-methylD-aspartate receptors: similarities to the action of zinc. $\mathrm{Br} \mathrm{J}$ Pharmacol 1988; 95: 95-102.

[46] Cai Z, McCaslin PP. Amitriptyline, desipramine, cyproheptadine and carbamazepine, in concentrations used therapeutically, reduce kainate- and N-methyl-D-aspartate-induced intracellular $\mathrm{Ca} 2+$ levels in neuronal culture. Eur J Pharmacol 1992; 219: 53-57.

[47] McCaslin PP, Yu XZ, Ho IK, Smith TG. Amitriptyline prevents Nmethyl-D-aspartate (NMDA)-induced toxicity, does not prevent NMDA-induced elevations of extracellular glutamate, but augments kainate-induced elevations of glutamate. J Neurochem 1992; 59: 401-5.

[48] Tao F, Liaw WJ, Zhang B, et al. Evidence of neuronal excitatory amino acid carrier 1 expression in rat dorsal root ganglion neurons and their central terminals. Neuroscience 2004; 123: 1045-51.

[49] Tao YX, Gu J, Stephens RL, Jr. Role of spinal cord glutamate transporter during normal sensory transmission and pathological pain states. Mol Pain 2005; 1: 30.

[50] Lim G, Wang S, Mao J. cAMP and protein kinase A contribute to the downregulation of spinal glutamate transporters after chronic morphine. Neurosci Lett 2005; 376: 9-13.

[51] Mao J, Sung B, Ji RR, Lim G. Chronic morphine induces downregulation of spinal glutamate transporters: implications in morphine tolerance and abnormal pain sensitivity. J Neurosci 2002; 22: 8312-23.

[52] Nakagawa T, Ozawa T, Shige K, Yamamoto R, Minami M, Satoh M. Inhibition of morphine tolerance and dependence by MS-153, a glutamate transporter activator. Eur J Pharmacol 2001; 419: 39-45.

[53] Tai YH, Tsai RY, Wang YH, et al. Amitriptyline induces nuclear transcription factor-kappaB-dependent glutamate transporter upregulation in chronic morphine-infused rats. Neuroscience 2008; 153 : $823-31$.

[54] Sitcheran R, Gupta P, Fisher PB, Baldwin AS. Positive and negative regulation of EAAT2 by NF-kappaB: a role for N-myc in TNFalpha-controlled repression. EMBO J 2005; 24: 510-20.

[55] Korn T, Magnus T, Jung S. Autoantigen specific T cells inhibit glutamate uptake in astrocytes by decreasing expression of astrocytic glutamate transporter GLAST: a mechanism mediated by tumor necrosis factor-alpha. FASEB J 2005; 19: 1878-80.

[56] Okada K, Yamashita U, Tsuji S. Modulation of $\mathrm{Na}(+)$-dependent glutamate transporter of murine astrocytes by inflammatory mediators. J UOEH 2005; 27: 161-70.

[57] Li LB, Toan SV, Zelenaia O, et al. Regulation of astrocytic glutamate transporter expression by Akt: evidence for a selective transcriptional effect on the GLT-1/EAAT2 subtype. J Neurochem 2006; 97: 759-71

[58] Davis KE, Straff DJ, Weinstein EA, et al. Multiple signaling pathways regulate cell surface expression and activity of the excitatory amino acid carrier 1 subtype of Glu transporter in C6 glioma. J Neurosci 1998; 18: 2475-85.

[59] Gonzalez MI, Susarla BT, Robinson MB. Evidence that protein kinase Calpha interacts with and regulates the glial glutamate transporter GLT-1. J Neurochem 2005; 94: 1180-88.

[60] Hughes EG, Maguire JL, McMinn MT, Scholz RE, Sutherland ML. Loss of glial fibrillary acidic protein results in decreased glutamate transport and inhibition of PKA-induced EAAT2 cell surface trafficking. Brain Res Mol Brain Res 2004; 124: 114-23.
[61] Trotti D, Peng JB, Dunlop J, Hediger MA. Inhibition of the glutamate transporter EAAC1 expressed in Xenopus oocytes by phorbol esters. Brain Res 2001; 914: 196-203.

[62] Fang H, Huang Y, Zuo Z. The different responses of rat glutamate transporter type 2 and its mutant (tyrosine 403 to histidine) activity to volatile anesthetics and activation of protein kinase C. Brain Res 2002; 953: 255-64.

[63] Kalandadze A, Wu Y, Robinson MB. Protein kinase C activation decreases cell surface expression of the GLT-1 subtype of glutamate transporter. Requirement of a carboxyl-terminal domain and partial dependence on serine 486. J Biol Chem 2002; 277: 45741-750.

[64] Zhou J, Sutherland ML. Glutamate transporter cluster formation in astrocytic processes regulates glutamate uptake activity. J Neurosci 2004; 24: 6301-6.

[65] Guillet BA, Velly LJ, Canolle B, Masmejean FM, Nieoullon AL, Pisano P. Differential regulation by protein kinases of activity and cell surface expression of glutamate transporters in neuronenriched cultures. Neurochem Int 2005; 46: 337-46.

[66] Nalepa I, Vetulani J. Involvement of protein kinase $C$ in the mechanism of in vitro effects of imipramine on generation of second messengers by noradrenaline in cerebral cortical slices of the rat. Neuroscience 1991; 44: 585-90.

[67] Mann CD, Vu TB, Hrdina PD. Protein kinase C in rat brain cortex and hippocampus: effect of repeated administration of fluoxetine and desipramine. Br J Pharmacol 1995; 115: 595-600.

[68] Budziszewska B, Jaworska-Feil L, Kajta M, Lason W. Antidepressant drugs inhibit glucocorticoid receptor-mediated gene transcription - a possible mechanism. Br J Pharmacol 2000; 130: 1385-93

[69] DeLeo JA, Tanga FY, Tawfik VL. Neuroimmune activation and neuroinflammation in chronic pain and opioid tolerance/hyperalgesia. Neuroscientist 2004; 10: 40-52.

[70] Guo W, Wang $\mathrm{H}$, Watanabe $\mathrm{M}$, et al. Glial-cytokine-neuronal interactions underlying the mechanisms of persistent pain. J Neurosci 2007; 27: 6006-18.

[71] Watkins LR, Milligan ED, Maier SF. Glial proinflammatory cytokines mediate exaggerated pain states: implications for clinical pain. Adv Exp Med Biol 2003; 521: 1-21.

[72] Ji RR, Befort K, Brenner GJ, Woolf CJ. ERK MAP kinase activation in superficial spinal cord neurons induces prodynorphin and NK-1 upregulation and contributes to persistent inflammatory pain hypersensitivity. J Neurosci 2002; 22: 478-85.

[73] Kawasaki Y, Zhang L, Cheng JK, Ji RR. Cytokine mechanisms of central sensitization: distinct and overlapping role of interleukin1 beta, interleukin-6, and tumor necrosis factor-alpha in regulating synaptic and neuronal activity in the superficial spinal cord. J Neurosci 2008; 28: 5189-94

[74] Bao-Gang Liu MD, Joseph RS, Jun-Ming Z. Tumor necrosis factor- $\alpha$ suppresses sustained potassium currents in rat small diameter sensory neurons. Open Pain J 2008; 1: 1-7.

[75] Mao J, Price DD, Mayer DJ. Mechanisms of hyperalgesia and morphine tolerance: a current view of their possible interactions. Pain 1995; 62: 259-74.

[76] Powell KJ, Hosokawa A, Bell A, et al. Comparative effects of cyclo-oxygenase and nitric oxide synthase inhibition on the development and reversal of spinal opioid tolerance. $\mathrm{Br} \mathrm{J}$ Pharmacol 1999; 127: 631-44.

[77] Raghavendra V, Tanga FY, DeLeo JA. Attenuation of morphine tolerance, withdrawal-induced hyperalgesia, and associated spinal inflammatory immune responses by propentofylline in rats. Neuropsychopharmacology 2004; 29: 327-34.

[78] Song P, Zhao ZQ. The involvement of glial cells in the development of morphine tolerance. Neurosci Res 2001; 39: 281 86.

[79] Tai YH, Tsai RY, Lin SL, et al. Amitriptyline suppresses neuroinflammation-dependent interleukin-10-p38 mitogen-activated protein kinase-heme oxygenase-1 signaling pathway in chronic morphine-infused rats. Anesthesiology 2009; 110: 1379-89.

[80] Lee TS, Chau LY. Heme oxygenase-1 mediates the antiinflammatory effect of interleukin-10 in mice. Nat Med 2002; 8: 240-46.

[81] Naito Y, Takagi T, Yoshikawa T. Heme oxygenase-1: a new therapeutic target for inflammatory bowel disease. Aliment Pharmacol Ther 2004; 20 (Suppl 1): 177-84. 
[82] Alam J, Wicks C, Stewart D, et al. Mechanism of heme oxygenase1 gene activation by cadmium in MCF-7 mammary epithelial cells. Role of p38 kinase and Nrf2 transcription factor. J Biol Chem 2000; 275: 27694-702.

[83] Zhang X, Bedard EL, Potter R, et al. Mitogen-activated protein kinases regulate $\mathrm{HO}-1$ gene transcription after ischemia-reperfusion lung injury. Am J Physiol Lung Cell Mol Physiol 2002; 283: L81529 .

[84] Da Silva J, Pierrat B, Mary JL, Lesslauer W. Blockade of p38 mitogen-activated protein kinase pathway inhibits inducible nitricoxide synthase expression in mouse astrocytes. J Biol Chem 1997; 272: $28373-80$

[85] Svensson CI, Hua XY, Protter AA, Powell HC, Yaksh TL. Spinal p38 MAP kinase is necessary for NMDA-induced spinal PGE(2) release and thermal hyperalgesia. Neuroreport 2003; 14: 1153-57.

[86] Svensson CI, Marsala M, Westerlund A, et al. Activation of p38 mitogen-activated protein kinase in spinal microglia is a critical link in inflammation-induced spinal pain processing. J Neurochem 2003; 86: 1534-44.

[87] Johnston IN, Milligan ED, Wieseler-Frank J, et al. A role for proinflammatory cytokines and fractalkine in analgesia, tolerance, and subsequent pain facilitation induced by chronic intrathecal morphine. J Neurosci 2004; 24: 7353-65.

[88] Milligan ED, Twining C, Chacur M, et al. Spinal glia and proinflammatory cytokines mediate mirror-image neuropathic pain in rats. J Neurosci 2003; 23: 1026-40.

[89] Jin SX, Zhuang ZY, Woolf CJ, Ji RR. p38 mitogen-activated protein kinase is activated after a spinal nerve ligation in spinal cord microglia and dorsal root ganglion neurons and contributes to the generation of neuropathic pain. J Neurosci 2003; 23: 4017-22.

[90] Kim SY, Bae JC, Kim JY, et al. Activation of p38 MAP kinase in the rat dorsal root ganglia and spinal cord following peripheral inflammation and nerve injury. Neuroreport 2002; 13: 2483-86.

[91] Tsuda M, Mizokoshi A, Shigemoto-Mogami Y, Koizumi S, Inoue $\mathrm{K}$. Activation of p38 mitogen-activated protein kinase in spinal hyperactive microglia contributes to pain hypersensitivity following peripheral nerve injury. Glia 2004; 45: 89-95.

[92] Cui Y, Chen Y, Zhi JL, Guo RX, Feng JQ, Chen PX. Activation of p38 mitogen-activated protein kinase in spinal microglia mediates morphine antinociceptive tolerance. Brain Res 2006; 1069: 235-43.

[93] Ono K, Han J. The p38 signal transduction pathway: activation and function. Cell Signal 2000; 12: 1-13.

[94] Zhang C, Baumgartner RA, Yamada K, Beaven MA. Mitogenactivated protein (MAP) kinase regulates production of tumor necrosis factor-alpha and release of arachidonic acid in mast cells. Indications of communication between p38 and p42 MAP kinases. J Biol Chem 1997; 272: 13397-402.

[95] van den Blink B, Juffermans NP, ten Hove T, et al. p38 mitogenactivated protein kinase inhibition increases cytokine release by macrophages in vitro and during infection in vivo. J Immunol 2001; 166: 582-87.

[96] Fields RD, Stevens-Graham B. New insights into neuron-glia communication. Science 2002; 298: 556-62.

[97] Verge GM, Milligan ED, Maier SF, Watkins LR, Naeve GS, Foster AC. Fractalkine (CX3CL1) and fractalkine receptor (CX3CR1) distribution in spinal cord and dorsal root ganglia under basal and neuropathic pain conditions. Eur J Neurosci 2004; 20: 1150-60.

[98] Narita M, Suzuki M, Narita M, et al. Neuronal protein kinase C gamma-dependent proliferation and hypertrophy of spinal cord astrocytes following repeated in vivo administration of morphine. Eur J Neurosci 2004; 19: 479-84.

[99] Campbell JN, Meyer RA. Mechanisms of neuropathic pain. Neuron 2006; 52: 77-92.

[100] Rintala DH, Holmes SA, Courtade D, Fiess RN, Tastard LV, Loubser PG. Comparison of the effectiveness of amitriptyline and gabapentin on chronic neuropathic pain in persons with spinal cord injury. Arch Phys Med Rehabil 2007; 88: 1547-60.

[101] Verdu B, Decosterd I, Buclin T, Stiefel F, Berney A. Antidepressants for the treatment of chronic pain. Drugs 2008; 68: 2611-32.

(c) Tai et al.; Licensee Bentham Open.

This is an open access article licensed under the terms of the Creative Commons Attribution Non-Commercial License (http://creativecommons.org/licenses/by-nc/3.0/) which permits unrestricted, non-commercial use, distribution and reproduction in any medium, provided the work is properly cited 